\title{
Catalytic Enantioselective Reactions with (Benzo)Pyrylium Salts
}

\author{
Sumi Josepha, Gaukhar Khassenovaª, and Olga García Mancheño*
}

\begin{abstract}
The use of (benzo)pyrylium salts as versatile synthetic building blocks has become an attractive platform for the preparation of valuable heterocyclic compounds. Besides other numerous direct applications of (benzo)pyryliums, the intrinsic electrophilic nature of these species or the dipole character of the related oxidopyrylium derivatives have been exploited towards the development of enantioselective transformations such as nucleophilic dearomatization and cycloaddition reactions. This review aims at providing an overview on the relevant catalytic enantioselective methodologies developed in the past years, which are presented considering the involved metal- and/or organic catalytic system, as well as the type of reaction.
\end{abstract}

Keywords: Enantioselective catalysis · Metal catalysis · O-heterocycles · Organocatalysis · Pyrylium salts

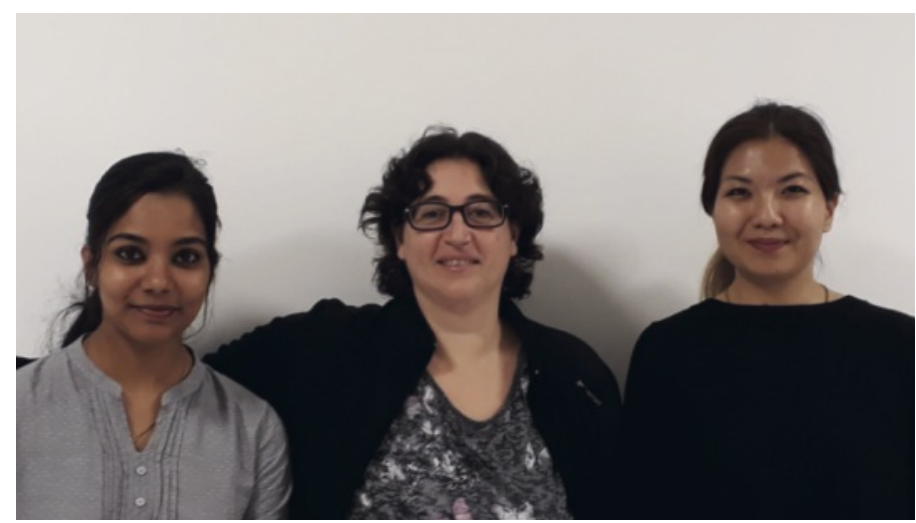

S. Joseph, O. García Mancheño and G. Khassenova

Sumi Joseph was born in Kerala, southernmost part of India. She earned her BSc in Chemistry from Calicut University in 2014 and did her MSc (2016) studies at Mahathma Gandhi University with specialization in Organic Chemistry. In 2018, she was awarded a DAAD fellowship and joined the research group of Prof. Dr. Olga García Mancheño at the Westfälische Wilhelms-Universität Münster, where she is currently in her second year of the $\mathrm{PhD}$ Program in Organic Chemistry. Her research interests include non-covalent asymmetric anion-binding organocatalysis and total synthesis of natural products.

Gaukhar Khassenova was born in Karaganda, an industrial city in central Kazakhstan. She completed both her Bachelor and Master studies in the Department of Organic Chemistry with specialization in Chemical Technology from the Karaganda State University. In 2019, she was awarded a DAAD fellowship and moved to Germany to pursue her doctoral studies in the group of Prof. Dr. Olga García Mancheño at the Institute of Organic Chemistry of the Westfälische Wilhelms-Universität Münster. Her work primarily focuses on non-covalent asymmetric anionbinding organocatalysis.

Olga García Mancheño received her PhD in 2005 from the Universidad Autónoma de Madrid under the supervision of Prof. J.C. Carretero. During her PhD she realized two short research stays with Prof. M.T. Reetz (MPI für Kohlenforschung) and
Prof. K.A. Jørgensen (University of Aarhus). She next moved to RWTH-Aachen for her postdoctoral research in the group of Prof. C. Bolm (2005-2008), followed by the start of her independent career at the University of Münster in 2008. In 2013, she was appointed as joint Chemistry Professor at the University of Regensburg and TUM-Campus Straubing, and since 2017 she is Professor for Organic Chemistry at the University of Münster.

\section{Introduction}

(Benzo)pyrylium salts are privileged six-membered aromatic heterocycles containing a positively charged oxygen atom. ${ }^{[1]}$ Important naturally occurring examples include the flavylium plant pigments, ${ }^{[2]}$ while synthetic derivatives present fluorescence $^{[3]}$ and photocatalytic activity, ${ }^{[4]}$ among other properties (Fig. 1, top). Moreover, the electronegativity of the oxygen atom in the aromatic ring induces a strong single perturbation, which makes it highly reactive towards nucleophilic additions leading to non-aromatic adducts, while it does not undergo typical aromatic electrophilic substitutions.

Several synthetic approaches have been developed for the preparation of (benzo)pyrylium salts (Fig. 1, bottom). ${ }^{[1]}$ The most common method relies on the condensation of carbonyl compounds in the presence of a strong acid (e.g. TfOH, $\mathrm{HBF}_{4}$, etc.) as shown in Fig. 1a. However, in most cases this method leads to 2,4,6-trisubstituted derivatives, in which all the nucleophilic sites are blocked. The second most employed synthesis of (benzo)pyrylium derivatives embraces substrates bearing a leaving group (LG) at the alpha position of the oxygen atom, which facilitates the elimination of this group (normally $\mathrm{RO}$ - or $\mathrm{RCO}_{2}-$ ) and formation of the corresponding salt (Fig. 1b). Besides these methodologies, several annulation reactions, as well as enolizations of (benzo)pyranones have also been widely used to generate the aromatic pyrylium core (Fig. 1c and 1d, respectively). Hence, multiple possibilities for the synthesis of these compounds exist, which make them very interesting synthetic building blocks with a rich chemistry as they can act as electrophiles (at the ortho and para positions) or, in the case of oxidopyryliums, as dipoles. ${ }^{[1]}$ Consequently, these salts can act as versatile synthetic intermediates for the preparation of highly added derivatives. However, most of the (benzo)pyrylium compounds obtained through the 
above-mentioned methods are quite unstable, except for the more robust 2,4,6-trisubstituted or flavin-type derivatives, and therefore they are normally formed in situ and reacted without prior isolation. Moreover, in the past few years, their extremely high potential for the synthesis of chiral molecules has gained more attention. Nonetheless, due to their intrinsic high reactivity, efficient catalytic enantioselective transformations are still scarce.

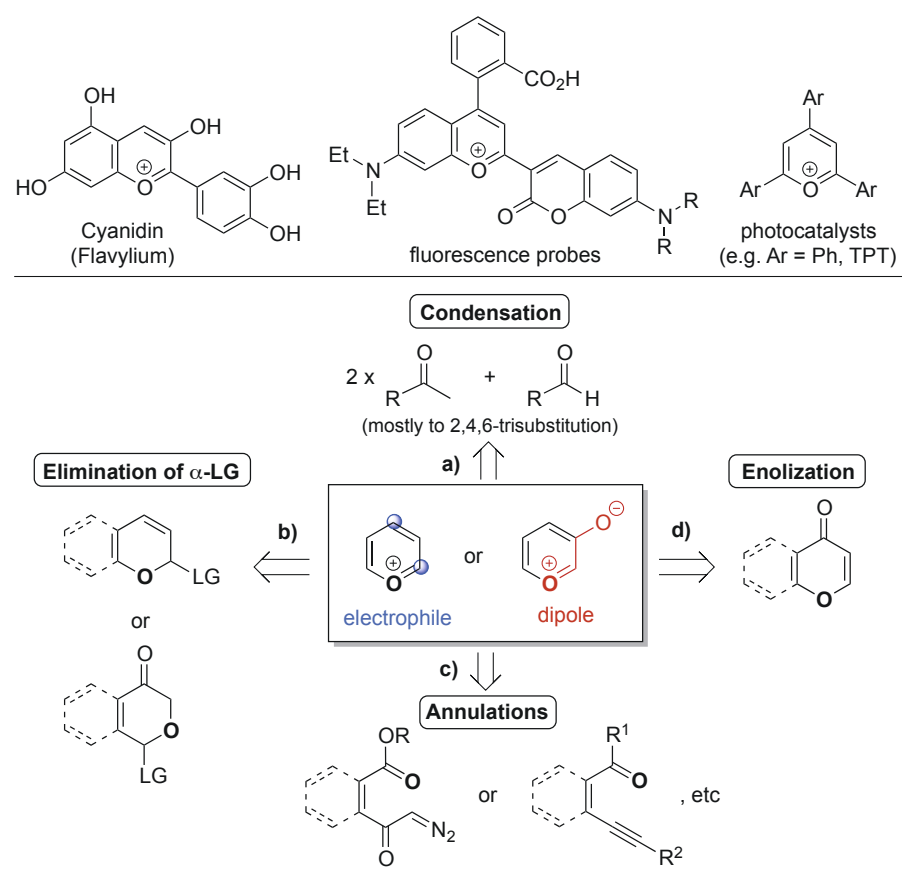

Fig. 1. Representative examples, synthetic approaches and reactivity of pyrylium derivatives.

In this review, we present the state of the art on catalytic enantioselective reactions involving (benzo)pyrylium salts. The review is divided in metal-catalyzed and organocatalytic approaches, which provide access to valuable $O$-heterocycles or important synthetic building blocks towards the synthesis of bioactive products. Thus, the methodologies discussed here are classified based on the catalytic system involved and type of key reaction, including diverse nucleophilic dearomatization and cycloaddition reactions.

\section{Metal Catalysis \\ 2.1 Metal-catalyzed Nucleophilic Dearomatization Reactions}

Ongoing efforts in this area are directed towards the development of effective methodologies for the synthesis of chiral $O$-heterocycles. In this regard, the stereo-controlled synthesis of biologically relevant chromenes and chromones can be achieved through the nucleophilic addition to a variety of in situ generated pyrylium-type electrophilic reactive species. Two main approaches have been employed to date, which involve i) an achiral metallic Lewis acid catalyst for the formation of the pyrylium species in combination with a chiral organocatalyst that activates the nucleophile, or ii) chiral organometallic nucleophiles, obtained by using a chiral metal catalyst formed with the appropriate chiral ligand. Thus, several lanthanoid-, gold- and copper-based catalyzed reactions have been described so far and are presented in the next sections.

\subsubsection{Lanthanoid Lewis Acid-catalyzed Reactions}

In 2010, Schaus and coworkers reported an example of enantioselective addition of boronates to chromene acetals involving a Lewis acid-promoted in situ formation of a reactive pyrylium ion intermediate (Scheme 1). ${ }^{[5]}$ To achieve this, they combined a tartaric acid amide as chiral Brønsted acid and a lanthanoid triflate complex as Lewis acid system to simultaneously activate the boronate and chromene, respectively. In this case, the formed reactive dioxoborolane intermediate added to the pyrylium ion, which was formed upon action of the achiral inorganic cerium or ytterbium Lewis acid.

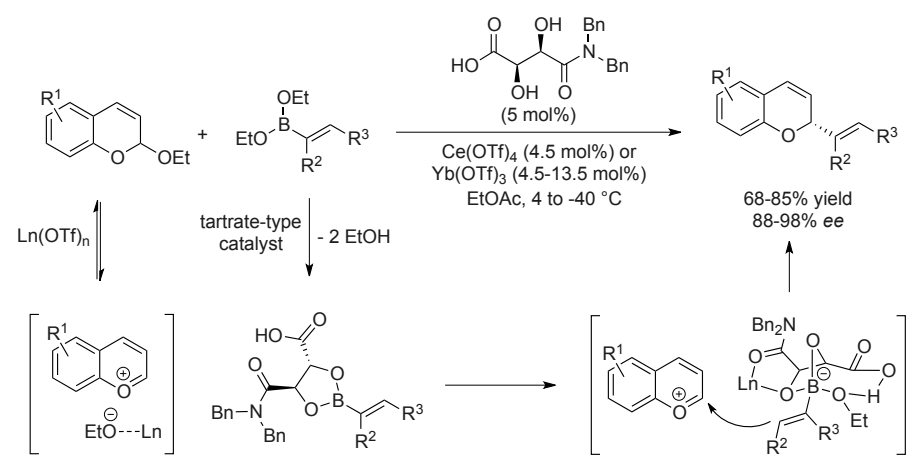

Scheme 1. Enantioselective addition of boronates to in situ-formed benzopyrylium ions.

In 2012, the Rueping group embraced a similar approach for the generation of the active chromenium intermediate from (iso) chromene acetals and described the first enantioselective addition of aldehydes to oxocarbenium ions for the synthesis of 2-substituted chiral chromenes (Scheme 2). ${ }^{[6]}$ They also used a dual catalytic system consisted of $\mathrm{Yb}(\mathrm{OTf})_{3}$ as achiral Lewis acid and a chiral imidazolidinone catalyst, in which the latter reacts with the carbonyl reagent to form the reactive enamine nucleophile. In order to facilitate the handling of the obtained chromene-aldehyde products, a final reduction to the corresponding alcohol was performed. Under these conditions, the desired chiral substituted chromenes were obtained in good yields and enantioselectivities up to $96 \%$ ee.

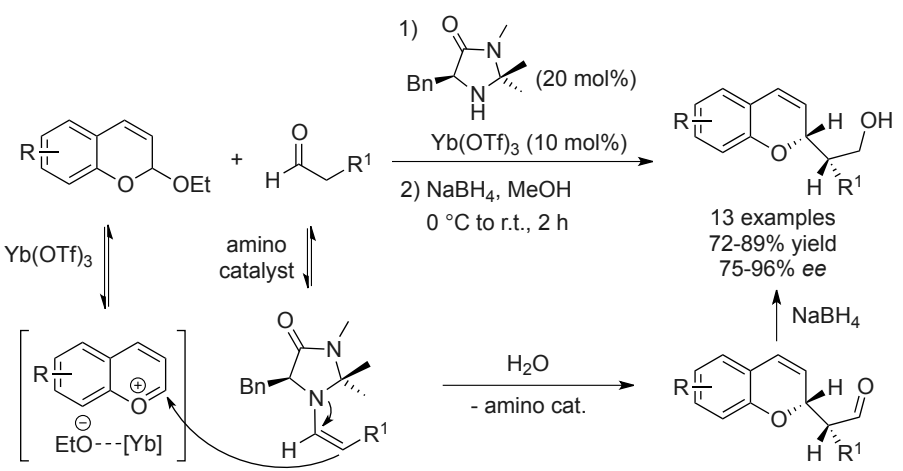

Scheme 2. Ytterbium-amino co-catalysis for the asymmetric addition of aldehydes to chromeniums.

Later on, Schaus and co-workers further investigated the effect of Lewis and Brønsted acid cooperative catalysis for the addition reaction of diazoesters to $2 \mathrm{H}$-chromene acetals (Scheme

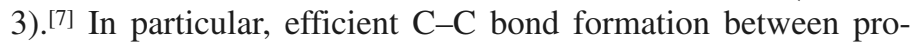
chiral oxocarbenium ions and ethyl diazoacetate were promoted using $\mathrm{Yb}(\mathrm{OTf})_{3}$ and commercially available chiral phosphoric acids to yield valuable chiral $2 \mathrm{H}$-chromene-diazomethane scaffolds. Although most of the examples were described with a non-chiral catalytic system, the asymmetric version was also explored. Thus, the best results were obtained with $(S)$-TRIP, providing the desired enantioenriched product in $62 \%$ ee $\left(R^{1}=H\right)$. 


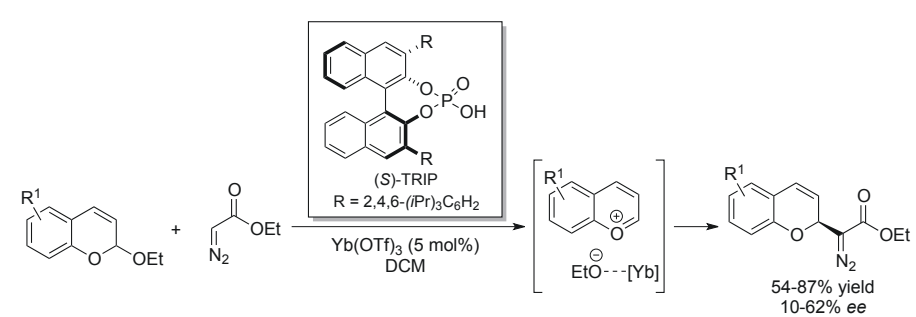

Scheme 3. Enantioselective addition of diazoesters to $2 \mathrm{H}$-chromene acetals.

\subsubsection{Gold-catalyzed Reactions}

Gold catalysts were also shown to be a good choice for conducting addition reactions on benzopyrylium-type intermediates. Consequently, Slaughter et al. reported in 2012 an enantioselective chiral gold(I) acyclic diaminocarbene complex catalyzed acetalization of in situ-formed isochromenylium intermediates via annulation reaction (Scheme 4). ${ }^{[8]}$ Interestingly, they observed that the stereoselective outcome correlates with the presence of $\mathrm{Au}$-arene interactions with electron-deficient aryl groups within the catalyst. Thus, the best results were obtained with a catalyst bearing a 3,5-( $\left(\mathrm{CF}_{3}\right)_{2} \mathrm{C}_{6} \mathrm{H}_{3}$ substitution at the bi-naphthyl backbone, providing the products in excellent enantioselectivities (up to $99 \%$ ee).

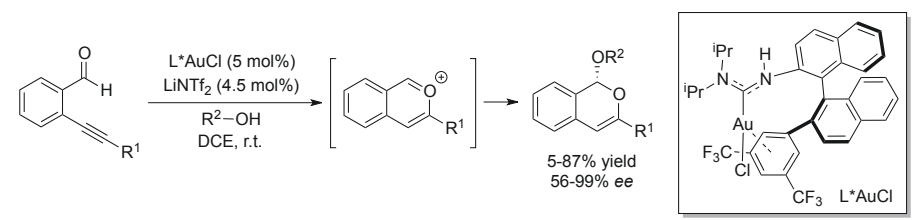

Scheme 4. Au(I)-diaminocarbene complex-catalyzed acetalization of isochromenylium intermediates.

\subsubsection{Copper-catalyzed Reactions}

As commented above, besides the use of achiral lanthanoid catalysts in combination with a chiral organocatalyst, chiral copper complexes have also been applied for achieving effective enantioselective additions to chromene and chromone derivatives. Hence, in 2015 Watson described the first enantioselective copper-catalyzed alkynylation of chromene acetals (Scheme 5). [9] Following his previous work on enantioselective transition-metal-catalyzed addition to prochiral oxocarbenium ions, ${ }^{[10]}$ a Lewis acid was also employed for the in situ formation of the benzopyrylium intermediate. In this case, $\mathrm{BF}_{3} \cdot \mathrm{Et}_{2} \mathrm{O}$ was applied as Lewis acid instead of TMSOTf. Moreover, a chiral copper acetylide was simultaneously formed in the presence of $\mathrm{CuI}$ and a chiral bis(oxazoline) ligand. Under these conditions, the desired chiral $\alpha$-alkynyl oxygen heterocycles were obtained in good yields and high enantioselectivities (up to $95 \%$ ee).

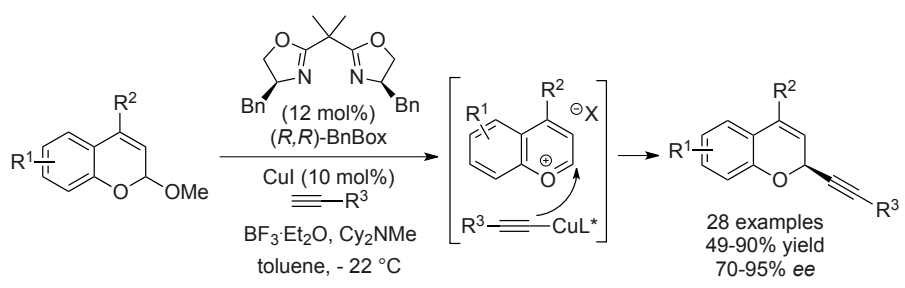

Scheme 5. Copper(I)-catalyzed additions of terminal alkynes.

Alternatively, the enantioselective alkynylation of 4-chromones was investigated independently by Aponick ${ }^{[11]}$ and Mattson. ${ }^{[12]}$ Embracing the same approach, a first treatment with a silane tri- flate is carried out in order to generate in situ the corresponding silyloxybenzopyrylium ion, which then reacts with a chiral copperacetylene. In 2019, Aponick described the alkynylation reaction using TMSOTf as silylating agent and $\mathrm{CuI}$ in combination with the chiral StackPhos ligand (Scheme 6, left). ${ }^{[11]}$ This method is high yielding over a broad substrate scope, providing a variety of useful chromanones in high enantioselectivity up to $95 \%$ ee. Within the framework of the research, the strong influence of the electronic nature of the substitution on the ligand on both the chemical yield and the selectivity was shown. In 2020, Mattson presented a highly stereoselective $\mathrm{Cu}$-catalyzed alkyne addition to an array of chromones using in this case TBSOTf as silylating reagent and $(S, S)$-BnBox as chiral bis(oxazoline) ligand (Scheme 6, right). ${ }^{[12]}$ Excellent levels of enantiocontrol were achieved, affording desirable 2-ethynyl chromanones in good yields and up to $98 \%$ ee.

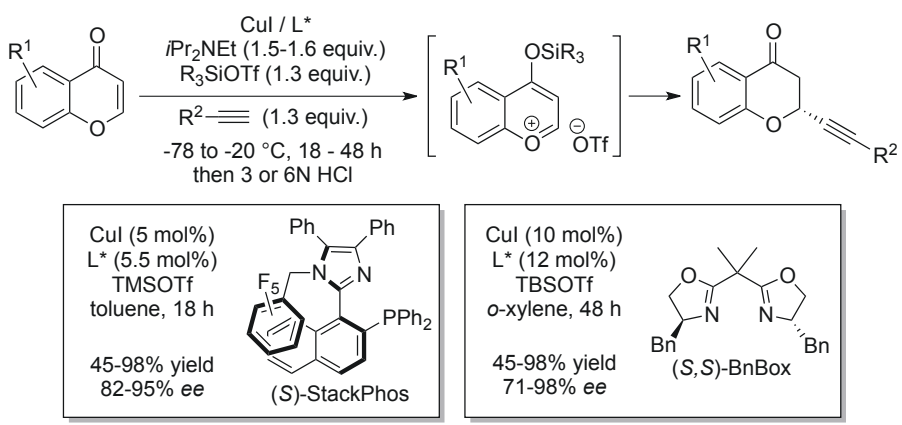

Scheme 6. Enantioselective alkynylation of chromones via in situ formed benzopyrylium salts.

\subsection{Enantioselective Metal-catalyzed Cycloadditions Involving (Benzo)pyrylium Intermediates}

\subsubsection{Reactions with 2-Benzopyrylium-4-olates}

Intramolecular carbenoid-carbonyl cyclizations represent one of the most effective approaches towards target synthesis of heterocyclic skeletons and biologically active natural products. Usually, the required non-isolable reactive carbonyl ylide intermediates are generated in situ from the corresponding diazo compound, for which rhodium catalysts demonstrated their superior efficiency in such transformations. Thus, in a first step, the reaction with 2-diazo-3,6-diketoesters leads to the formation of the metal-carbonyl ylide. This intermediate can then react with various alkene dipolarophiles as reaction partners, which normally proceed in the presence of a rare earth metal triflate complex of chiral 2,6-bis(oxazolinyl)pyridine (Pybox) as chiral Lewis acid co-catalyst in order to achieve highly enantioselective 1,3-dipolar cycloadditions reactions.

In 1997, the first example of catalytic enantioselective tandem carbonyl ylide formation-cycloaddition using unsaturated $\alpha$-diazo$\beta$-keto esters in the presence of $\mathrm{Rh}_{2}(S \text {-DOSP })_{4}$ was reported by Hodgson and co-workers, obtaining a moderate enantioselectivity (52\% ee) (Scheme 7, top). ${ }^{[13]}$ The same group made further efforts to extend this chemistry to other types of substrates with different chiral dirhodium complexes for related tandem oxidopyrylium formation - intramolecular 1,3-dipolar cycloaddition reactions, however in all cases very poor enantioselectivities were obtained ( $<20 \%$ ee; Scheme 7, bottom). ${ }^{[14]}$ Despite the moderate chiral inductions within these initial reports, a chiral rhodium(II)-bounded ylide-type was then proposed as key intermediate, which was crucial for the later development of further methodologies. ${ }^{[13,15]}$

As a result, the enantioselective rhodium-catalyzed generation of carbonyl ylides and their study in cycloaddition reactions has become a vast and rapidly growing field. ${ }^{[15]}$ However, only few examples with the challenging (benzo)pyrylium derivatives 


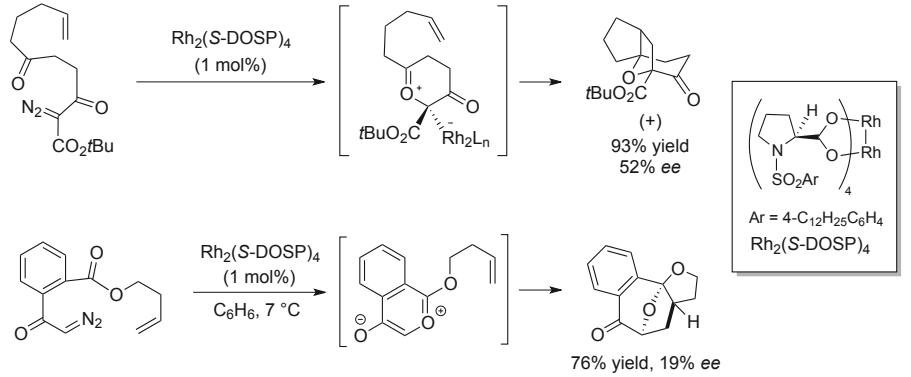

Scheme 7. Pioneer asymmetric Rh-catalyzed cycloaddition with carbonyl ylides.

have been described. ${ }^{[16]}$ Thus, in 2002, Suga et al. developed the first asymmetric 1,3-dipolar cycloaddition reaction of 2-benzopyrylium-4-olates catalyzed by a chiral 2,6-bis(oxazolinyl) pyridine (PyBox)-rare earth metal triflate complex as chiral Lewis acid catalyst (Scheme 8, A). ${ }^{[16 a]}$ The substrate for the cycloaddition reaction, the 2-benzopyrylium-4-olate, was formed from 2-methoxycarbonyl- $\alpha$-diazoacetophenone $\left(\mathrm{R}^{1}=\mathrm{Me}\right)$ using commercially available $\mathrm{Rh}_{2}(\mathrm{OAc})_{4}$ in catalytic amounts $(2$ mol\%). Depending on the dipolarophile reagent used, two different Lewis acid catalytic systems were identified. The Sc(III)Pybox-iPr $(10 \mathrm{~mol} \%)$ proved highly selective for the reactions with benzyloxyacetaldehydes and pyruvates $\left(\mathrm{R}^{2}=\mathrm{H}\right)$, affording the endo-adducts in a high enantioselectivity up to $93 \%$ ee and reverse exo-selectivity with $87 \%$ ee, respectively. Alternatively, the $\mathrm{Yb}$ (III)-Pybox-Ph catalyst provided the best results with 3-acryloyl-2-oxazolidinone $\left(\mathrm{R}^{4}=\mathrm{H}\right)$, this time giving the exo-adduct (exo/endo $=88: 12$ ) with an extremely high enantioselectivity of $98 \%$ ee. A few years later, the same group was able to extend the method to other diazoacetophenones and improve the reaction with pyruvates and $\alpha$-ketoesters $\left(\mathrm{R}^{2}=\mathrm{Alk}, \mathrm{Ph}, \mathrm{CO} \mathrm{Et}_{2}\right)$ by adding a different organic acid as additive (10-20 mol\% TFA instead of pyruvic acid) using the same co-catalysis with $\mathrm{Rh}_{2}(\mathrm{OAc})_{4}$ and the chiral PyBox-lanthanoid metal complexes (Scheme 8, B). [16b] Based on these results, the stereoselective cycloaddition reactions with 3-(2-alkenoyl)-2-oxazolidinones as dipolarophiles catalyzed by PyBox- $\mathrm{Yb}(\mathrm{OTF})_{3}$ complexes was further developed (Scheme 8, C). ${ }^{[16 c]}$ They found out that the use of the 5-substituted Pybox$\mathrm{Ph}$ ligand $(20 \mathrm{~mol} \%)$ led to cycloaddition reaction products with high endo- (>99:1) and enantioselectivity (up to $96 \%$ ee), while a disubstitution $\left(\mathrm{PyBox}-\mathrm{Ph}_{2}\right)$ provided the exo-adducts with lower selectivities (exo/endo $\leq 82: 18$ ).

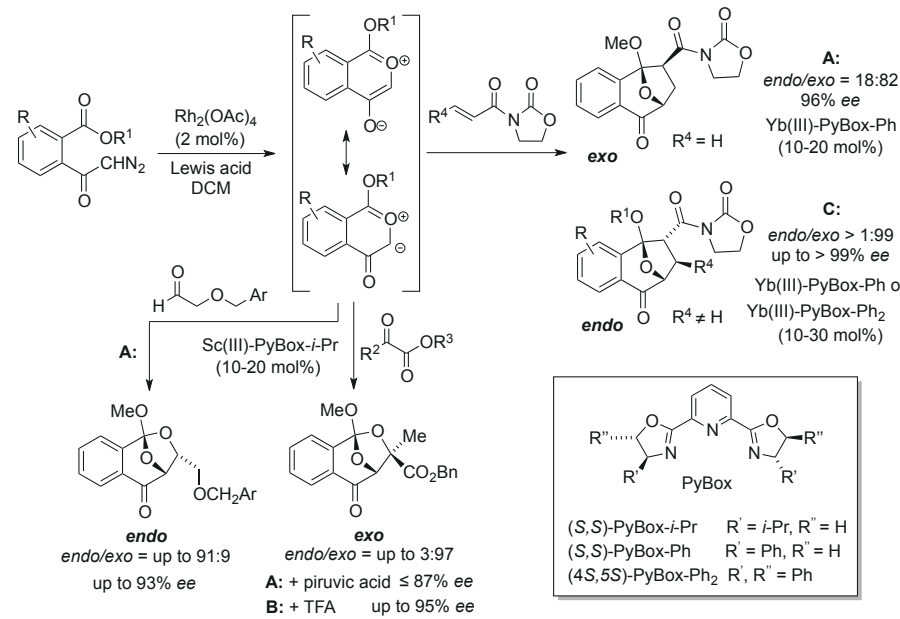

Scheme 8. One-pot Rh-mediated generation of 2-benzopyrylium4-olates for Sc(II) or Yb(III)-PyBox catalyzed 1,3-dipolar cycloaddition reactions by Suga et al.
In 2010, Suga expanded his study of Rh and chiral Lewis acid co-catalyzed asymmetric cycloadditions of cyclic carbonyl ylides with olefinic substrates (Scheme 9). ${ }^{[16 \mathrm{~d}]}$ This time, other lanthanoids such as $\mathrm{Eu}(\mathrm{OTf})_{3}, \mathrm{Ho}(\mathrm{OTf})_{3}, \mathrm{Gd}(\mathrm{OTf})_{3}$ or Lu(OTf) $(10 \mathrm{~mol} \%)$ were used as Lewis acids in combination with the $(4 S, 5 S)-\mathrm{PyB}$ ox- $\mathrm{Ph}_{2}$ chiral ligand, which allowed the cycloaddition reaction with electron-rich dipolarophiles such as allyl alcohol, 2,3-dihydrofuran, butyl-tert-butyldimethylsilylketene acetal and vinyl ethers, affording the adducts in moderate and good yield and moderate to high enantioselectivities depending on the addition sequence, the dipolarophile and the Lewis acid used (up to $96 \%$ ee). Alternatively, a binaphthyldiimine (BINIM)-Ni(II) complex $(10 \mathrm{~mol} \%)$ was more effective in the reaction with butyl or cyclohexyl vinyl ethers, leading to the corresponding products in high enantioselectivities (up to $97 \%$ ee).

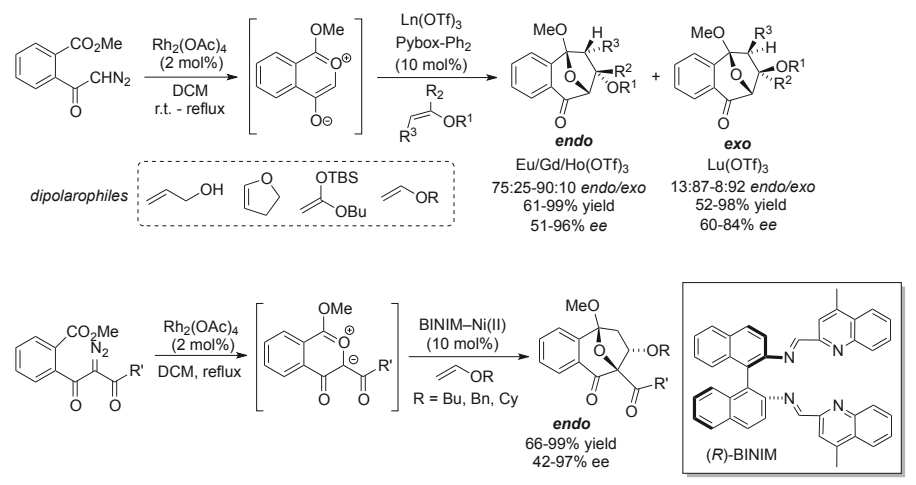

Scheme 9. Asymmetric cycloadditions of cyclic carbonyl ylides with olefinic substrates.

\subsubsection{Reactions Comprising Metallo-benzopyrylium Complexes}

Several highly enantioselective oxa-Diels-Alder cycloaddition reactions of in situ generated metallo-isochromenyliums have been described, leading to efficient one-step access to a broad spectrum of enantiopure natural product-like derivatives of medicinal interest.

In 2009, Tanaka reported the first cooperatively catalyzed cascade reaction by cationic rhodium(I) and silver(I) complexes via isochromenylium intermediates between $o$-alkynylbenzaldehydes and $N$-substituted isatin derivatives in the presence of a ferrocenylphosphine ligand complex (Scheme 10). ${ }^{[17]}$ As a result, the corresponding helical tetrasubstituted alkenes in high enantio- and diastereoselectivities were obtained. Accordingly, a possible mechanism was proposed starting from the intramolecular reaction of the 2-alkynylbenzaldehyde to form rhodiumbenzopyrylium complex A. Although there is no precedent for a cycloaddition between the metalbenzopyrylium intermediate and a $\mathrm{C}=\mathrm{O}$ bond, it was anticipated that the reaction with isatin could form $\mathbf{B}$. The intermediate $\mathbf{B}$ further evolved to a rhodacycle $\mathbf{C}$, which finally gave the tetrasubstituted alkene upon elimination of the Rh(I) catalytic species.

Later, Yao et al. reported in 2013 the enantioselective oxaDiels-Alder cycloaddition reaction involving isochromenium intermediates by cooperative binary catalysis employing $\mathrm{Pd}(\mathrm{OAc})_{2}$ and (S)-Trip (Scheme 11). ${ }^{[18]}$ Particularly, they described the asymmetric cascade annulation between 2-hydroxystyrenes and 2-alkynylbenaldehydes or 1-(2-alkynylphenyl)ketones affording the corresponding bridged cyclic products with good to excellent enantioselectivities (up to $>99.5 \%$ ee). This method could be applied with high efficiency for a broad spectrum of substrates, allowing the simultaneous creation of dense multiple chiral centers including quaternary carbons.

In the following year, Yao extended his research on enantioselective annulation via pyrylium-type intermediates using syner- 


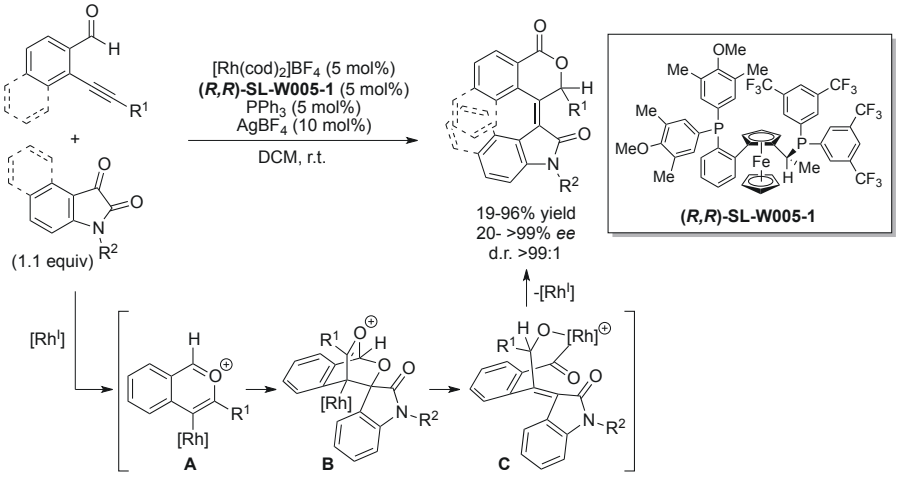

Scheme 10. $\mathrm{Rh}(1)$ and $\mathrm{Ag}(1)$ co-catalyzed synthesis of chiral helical tetrasubstituted alkenes.
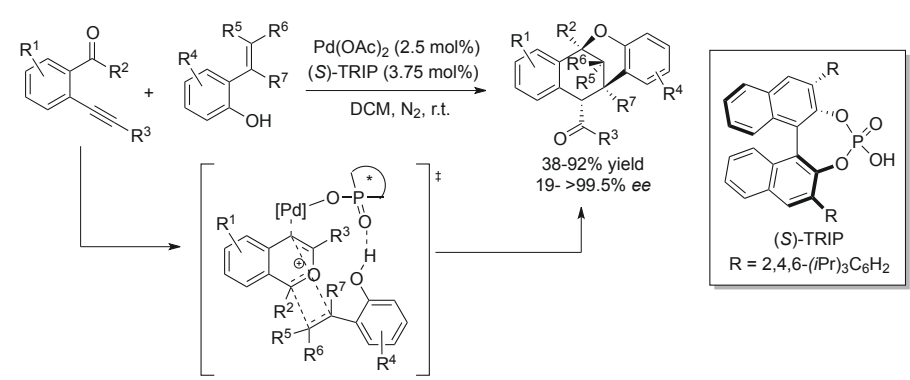

Scheme 11. Enantioselective oxa-Diels-Alder cycloaddition via isochromenium intermediates.

getic catalysis by applying AgOAc and the chiral phosphoric acid $(S)$-TRIP as catalytic system (Scheme 12). ${ }^{[19]}$ In this case, they investigated the reaction of 3-alkynylacrylaldehydes with styrenetype olefins, affording the corresponding products with moderate to excellent enantioselectivities (up to $95 \%$ ee). The proposed mechanism implies a cascade reaction pathway that involves the in situ generation of a pyrylium intermediate by $\mathrm{Ag}(\mathrm{I})$-catalyzed alkyne/carbonyl cycloisomerization, followed by an oxa-[4+2]cycloaddition and an intramolecular nucleophilic substitution.

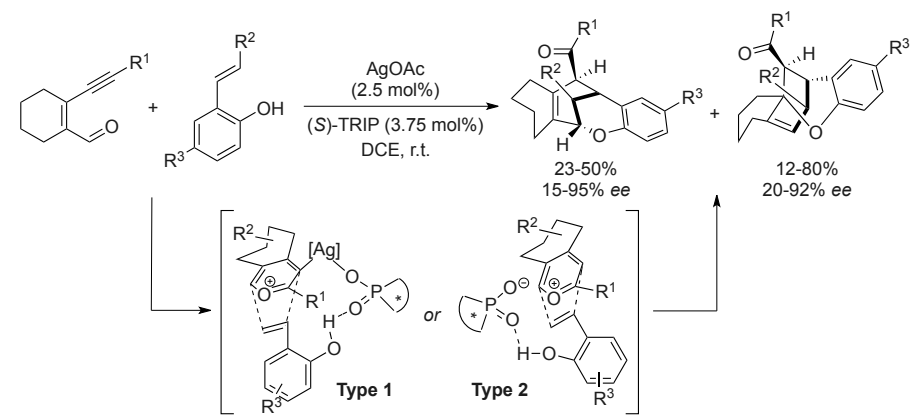

Scheme 12. Silver-TRIP-catalyzed enantioselective annulation of 3-alkynylacrylaldehydes.

More recently, in 2019, Tanaka and co-workers reported an asymmetric intramolecular [4+2]-annulation of ene-yne-carbonyls via benzopyrylium-type intermediates catalyzed by a cationic gold(I)/(R)-H $-\mathrm{H}_{8}$-binap complex (Scheme 13). ${ }^{20]}$ Under these conditions, the targeted chiral tricyclic compounds bearing two stereogenic centers were obtained as single diastereomers but with only moderate enantiomeric excess (up to 53\% ee). Additionally, when more sterically demanding naphthalene-linked ene-yne carbonyls reacted with the gold(I) catalyst, not only [4+2]-annulation took place, but also [3+2]-annulation adducts were obtained as minor products with good enantioselectivity (up to $93 \%$ ee).

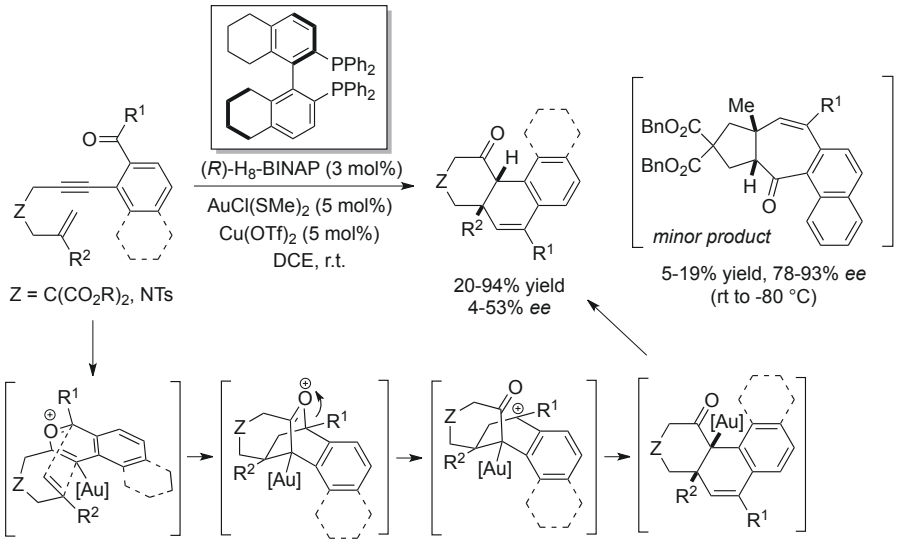

Scheme 13. Asymmetric Au-catalyzed intramolecular [4+2]-annulation of ene-yne-carbonyls.

\section{Organocatalysis}

Enantioselective organocatalysis has become an important tool in organic synthesis for the efficient preparation of chiral molecules. ${ }^{[21]}$ Particularly, highly efficient chiral Brønsted acid, ${ }^{[22]}$ hydrogen-bonding[23] and amino ${ }^{[24]}$ catalysts have been developed for a broad spectrum of asymmetric transformations, including enantioselective organocatalytic reactions of (benzo) pyrylium derivatives, which will be discussed in the next sections.

\subsection{Brønsted Acid-catalyzed Reactions}

The first asymmetric Brønsted acid (BH) catalyzed hydrogenation of benzopyrylium ions was reported by Rueping and coworkers (Scheme 14). ${ }^{[25]}$ They described a photo-assisted in situ generation of 2-chromenols derived from chalcones, followed by benzopyrylium ion formation and hydrogenation employing a Hantzsch allyl ester (HaE). A mechanism involving a Brønsted acid-catalyzed chromenol protonation and successive elimination of a $\mathrm{H}_{2} \mathrm{O}$ molecule resulted in an intermediary chiral ion pair consisting of the benzopyrylium and the chiral $\mathrm{B}^{-}$anion. Then, subsequent enantioselective hydride nucleophilic addition at the 4-position of the benzopyrylium ion gave rise to the desired $4 H$-chromenes with a broad substrate scope.
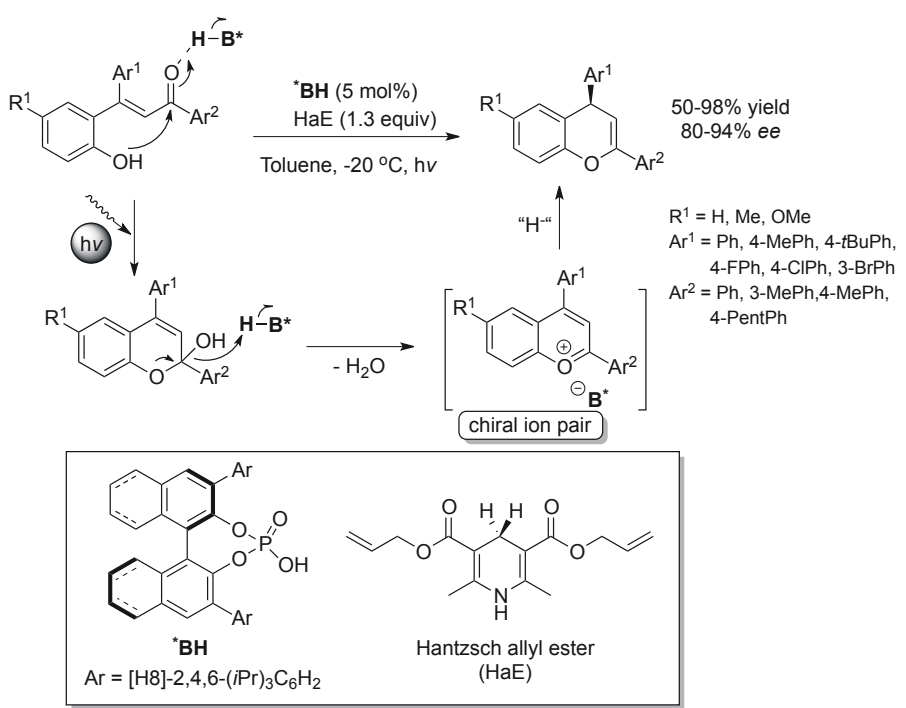

Scheme 14. Asymmetric ion-pair catalysis for the enantioselective hydrogenation of pyrylium ion.

Shortly after, Terada and coworkers reported a similar enantioselective reduction of benzopyrylium ions with the Hantzsch ester (HE) in the presence of the same chiral Brønsted acid $(* \mathrm{BH})$ 
(Scheme 15). The only difference was that the benzopyrylium is derived directly from the corresponding chromenol, showing the best enantioselectivities (up to $96 \%$ ee) when substituted as tertbutyl ether in the 6-position. ${ }^{[26]}$

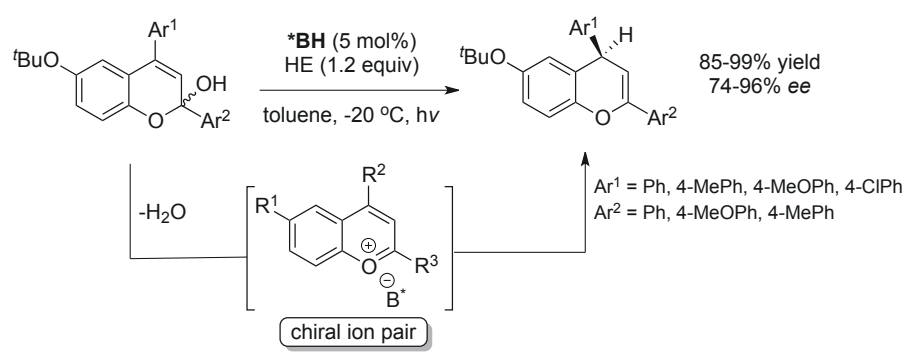

Scheme 15. Chiral anion catalysis of the enantioselective reduction of 1-benzopyrylium ion.

An alternative example of the asymmetric reaction of the planar isobenzopyrylium species was reported by Sun and coworkers in 2014 (Scheme 16). ${ }^{[27]}$ They proposed a highly enantio- and diastereoselective synthesis of dihydronaphthalenes by nucleophilic addition of a styryl boronic acid to isobenzopyrylium ions in the presence of a chiral phosphoric acid as catalyst $(* \mathrm{BH})$ and $\mathrm{MgSO}_{4}$ as the additive. The excellent stereocontrol is presumably attributed to the unusual chiral counteranion generated in situ from the chiral phosphoric acid and the boronic acid nucleophile, as well as the employed ethylenglycol leaving group that also activates the nucleophile. Moreover, the reaction is compatible to both electron-withdrawing and electron-donating groups on the acetal substrates.

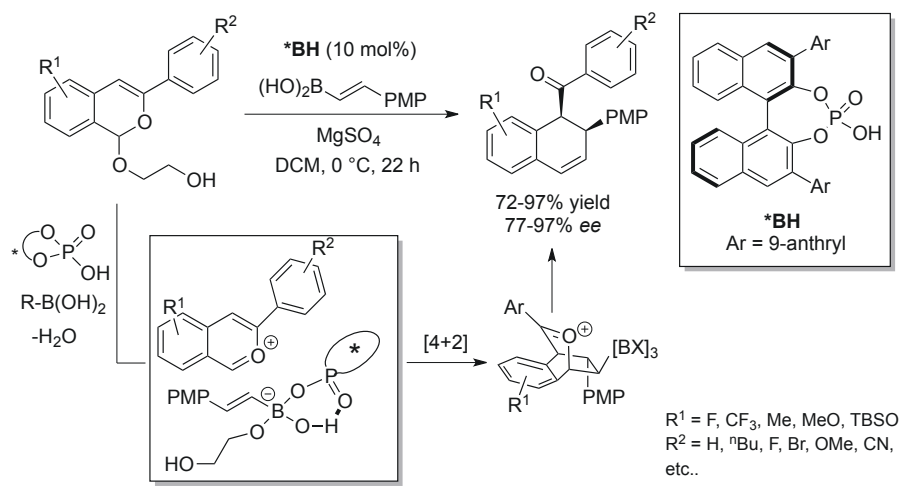

Scheme 16. Enantio- and diastereoselective synthesis of 1,2-dihydronaphthalenes from isobenzopyryliums.

Likewise, Toste and coworkers employed chiral phosphoric acids $(* \mathrm{BH})$ for the enantioselective synthesis of flavonoids from benzopyrylium ions using chiral anion phase transfer (CAPT) catalysis (Scheme 17). ${ }^{[28]}$ The proposed biosynthetic pathway proceeds through the generation of a soluble chiral benzopyrylium ion pair from an insoluble benzopyrylium cation in the presence of the deprotonated chiral phosphoric acid catalyst. Thus, this soluble ion pair can then react with phenols to generate the enantioenriched flavonoid-type products.

\subsection{Hydrogen-bond Donor-catalyzed Nucleophilic Additions to (Benzo)pyryliums}

Chiral hydrogen-bond (HB) donor catalysis ${ }^{[23]}$ has also been employed to effect the activation of (benzo)pyrylium electrophiles towards cycloaddition or nucleophilic addition reactions.

As the first non-catalytic example using stoichiometric HBdonors as promoters, in 2006, Porco and coworkers described

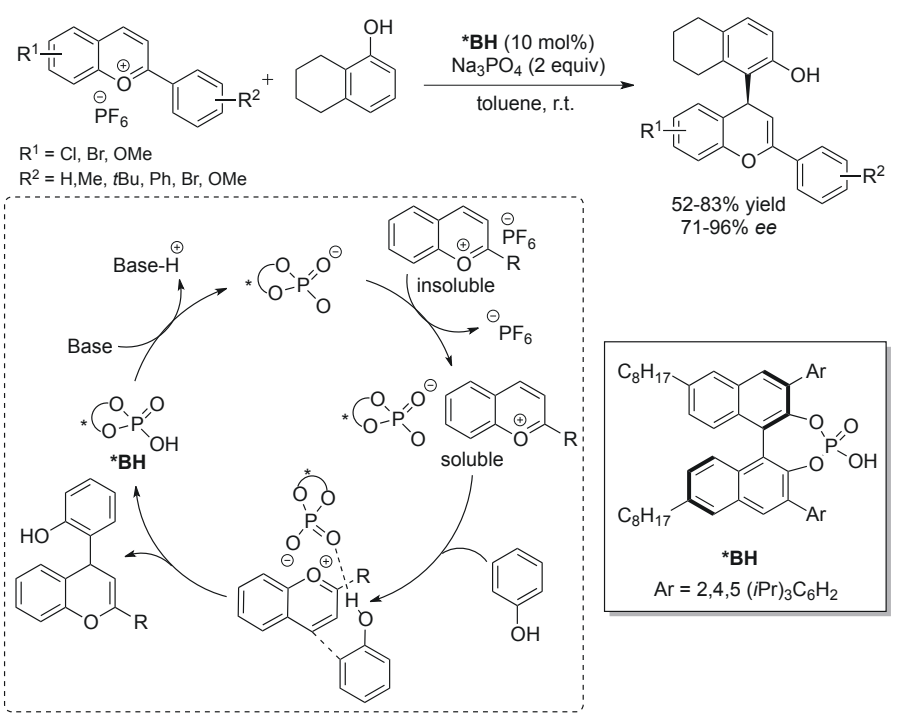

Scheme 17. CAPT-catalyzed enantioselective addition of phenol to benzopyrylium ion.

the asymmetric synthesis of methyl rocaglate ${ }^{[29]}$ by an enantioselective [3+2]-photocycloaddition of an oxidopyrylium derivate with methyl cinnamate in the presence of a TADDOL derivative I (Scheme 18). ${ }^{[30]}$ The observed diastero- and enantioselectivity was rationalized by the formation of an assembly between the oxidopyrylium and the catalysts by hydrogen bonding with the free hydroxyl groups of TADDOL-I, stabilizing the dipole.

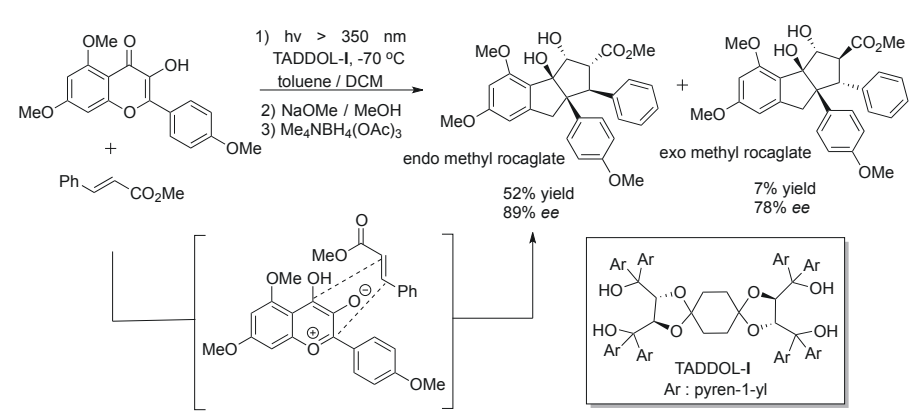

Scheme 18. Synthesis of methyl rocaglate via asymmetric [3+2]-photocycloaddition of oxidopyrylium ions.

However, despite the high synthetic potential of HB-catalysis, the first organocatalytic enantioselective reaction of benzopyryliums was reported by Mattson and coworkers in 2016 (Scheme 19). ${ }^{[31]}$ They developed an intermolecular addition to 4-chromenones via the corresponding 4-siloxy benzopyrylium triflate intermediates in the presence of 3,3'-substituted BINOL-based silanediol as a H-bond donor catalyst. The reaction mechanism proceeds via the in situ generation of a chiral benzopyrylium ion pair from a chromenone and silyl triflate in the presence of the bidentate silanediol catalyst, followed by a biased addition of silyl ketene acetals as nucleophiles. However, this method required a high catalyst loading of $20 \mathrm{~mol} \%$ to achieve moderate enantioselectivities. Moreover, the substrate scope of this reaction was examined, showing that chromenones substituted with electronwithdrawing groups were higher yielding and more selective than substrates possessing electron-donating groups.

A few years later, the group of García Mancheño developed a related highly enantioselective nucleophilic dearomatization reaction of in situ formed pyrylium-type derivatives using a chiral multi-coordination triazole anion-binding catalyst (Scheme 20). ${ }^{[32]}$ The high activity observed with this type of catalyst, which allows remarkably low catalytic loadings (down to $0.05 \mathrm{~mol} \%$ ), is 


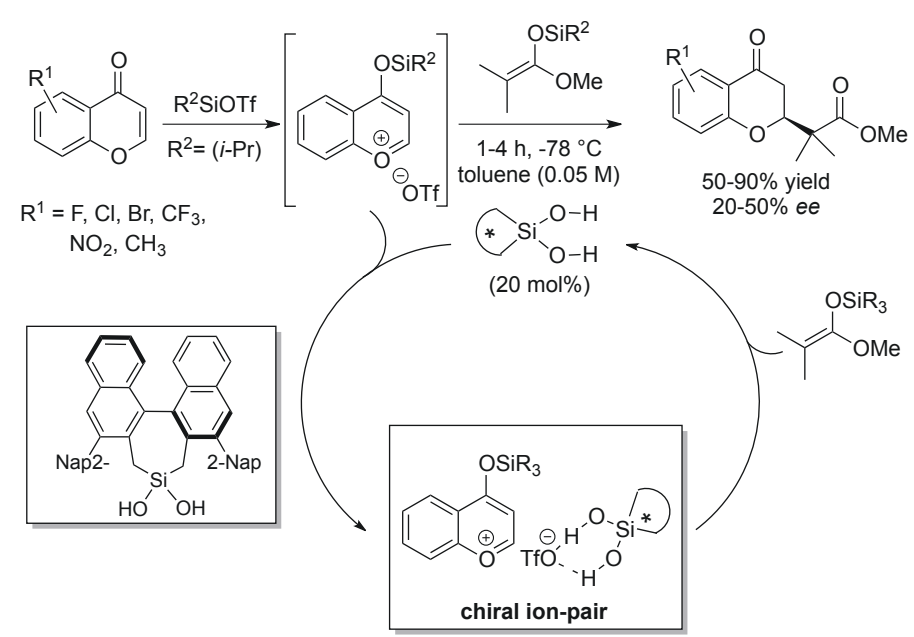

Scheme 19. Silanediol-catalyzed enantioselective benzopyrylium ion functionalization.

due to the presence of four strongly polarized $\mathrm{C}-\mathrm{H}$ bonds at the triazole units and further multiple coordination sites of neighboring $\mathrm{C}-\mathrm{H}$ bonds. Moreover, they are able to form helical structures with distinct anion-binding pockets, as well as to potentially interact with the pyrylium species through the lone pair of the nitrogen atoms in the triazole rings. This method proved to be highly enantioselective (up to $96 \%$ ee) and broad in scope, allowing not only the reaction with the more stable chromenium salts, but also with simple pyryliums, with no ring opening or decomposition of the latter.

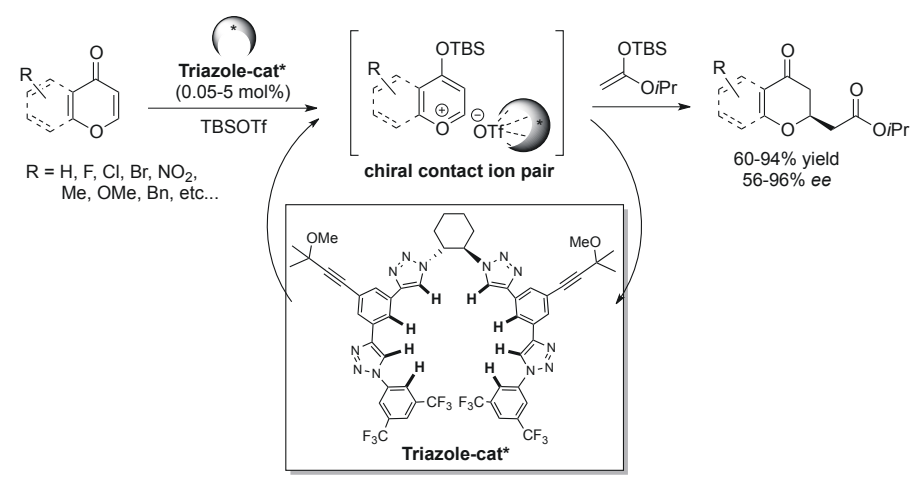

Scheme 20. Dearomatization of pyrylium derivatives using helical multidentated anion-binding catalysts.

\subsection{Amino and Dual Amino-HB-donor Catalysis}

In 2009, Cozzi and coworkers described an oxidative benzylic $\mathrm{C}-\mathrm{H}$ functionalization of $4 \mathrm{H}$-flavene with octanal in the presence of a MacMillan imidazolidinonium-type catalyst. In this reaction, DDQ was used as stoichiometric oxidant to generate in situ the flavylium species, which was attacked by the nucleophilic enamine formed from the aldehyde and chiral amino-catalysts, yielding the corresponding 4-functionalized derivative in a moderate $62 \%$ ee. ${ }^{[33]}$ These initial results inspired them to pursue the synthesis of further chiral $4 H$-flavenes by enantioselective $\alpha$-alkylation of aldehydes with stable flavylium triflate, leading to the desired products in moderate to good yields, diastereoselectivities and enantioselectivities (Scheme 21). ${ }^{[34]}$

Besides this nucleophilic enamine-type addition, amino and the combination of amino and HB-donor catalysis have also been reported for enantioselective cycloadditions. Pyrylium ylides are versatile and reactive species that have been used widely in natural product synthesis, particularly due to their ability to undergo $[5+2]$-cycloaddition reactions. ${ }^{[35]}$ In this regard, the first example of asymmetric [5+2]-cycloaddition involving 3-oxidopyrylium-

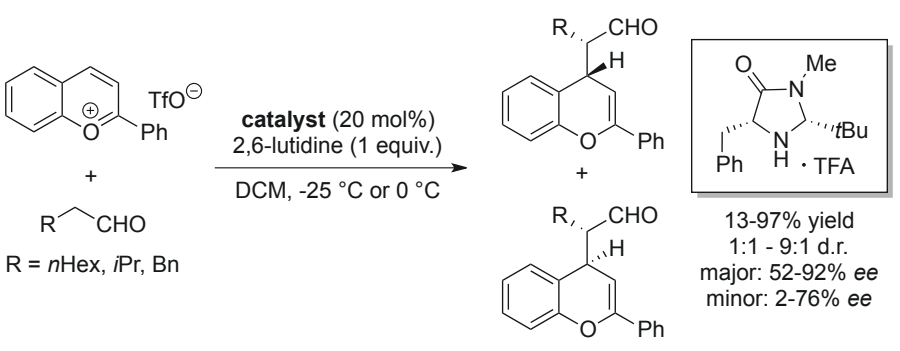

Scheme 21. Organocatalytic stereoselective oxidative benzylic C-H functionalization of flavenes.

type intermediates under H-bond donor cooperative catalysis was reported by Jacobsen and co-workers in 2011 (Scheme 22). ${ }^{[36]}$ They identified a cooperative chiral aminothiourea-achiral thiourea catalytic system for the intramolecular [5+2]-cycloadditions of pyrylium ylides with olefins to access tricyclic structures. This reaction relies on properties of the achiral thiourea anion-binding co-catalyst II to facilitate the cleavage of corresponding carboxylate anion, while the chiral amino catalyst III activates the substrate by covalent bonding to form the reactive 3 -aminopyrylium intermediate. Moreover, the addition of acetic acid as a second cocatalyst enhanced the yield with no effect on the product enantioselectivity. The substrate scope of this reaction was examined, showing that various terminal substituted olefins and allenes were tolerated, despite diminished reactivity upon increased substitution, while alkyne-bearing substrates were unreactive under the reported reaction conditions.

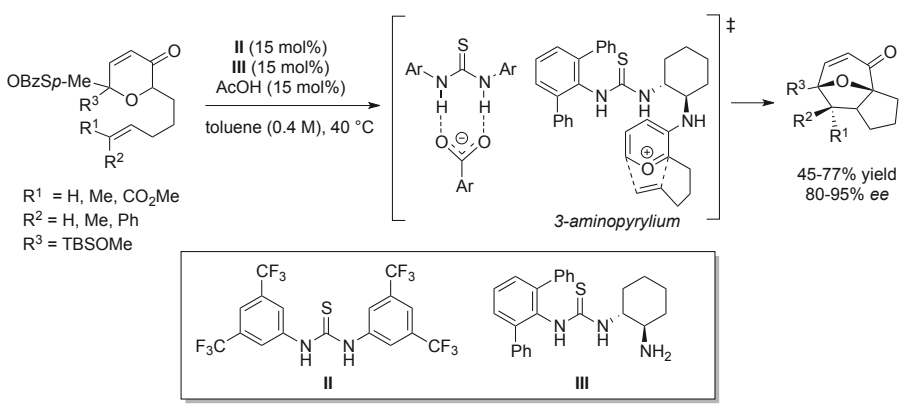

Scheme 22. Intramolecular enantioselective oxidopyrylium-based [5+2]-cycloadditions.

In a continuation of the work, in 2014, the author reported a related intermolecular version of enantioselective [5+2]-cycloadditions of 3,4,5-trifluorobenzoyloxypyrylium salts with electronrich olefins promoted by the same co-catalytic system to obtain the corresponding 8-oxabicyclo[3.2.1] octane derivatives (Scheme 23). ${ }^{[37]}$ The need for an electron-rich $2 \pi$-reactant such as vinyl ethers is consistent with a mechanism involving a cationic, electron-poor aminopyrylium intermediate. Regarding the substrate scope, pyranones bearing longer alkyl chains at the 6-position show high enantioselectivities, whereas $\beta$-branching in the side chain had a deleterious effect on the reactivity.
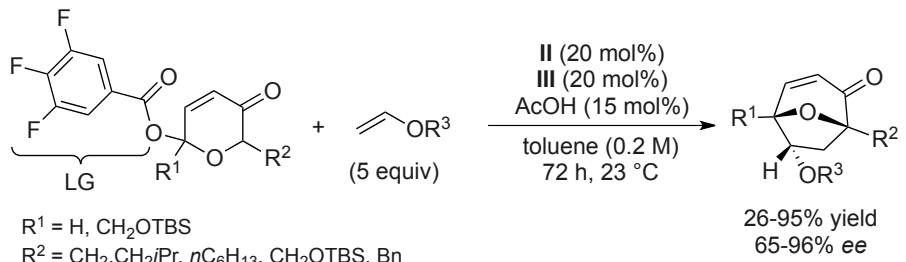

$\mathrm{R}^{1}=\mathrm{H}, \mathrm{CH}_{2} \mathrm{OTBS}$
$\mathrm{R}^{2}=\mathrm{CH}_{2}, \mathrm{CH}_{2} \mathrm{Pr}$,

$\mathrm{R}^{2}=\mathrm{CH}_{2}, \mathrm{CH}_{2} i \mathrm{Pr}, n \mathrm{C}_{6} \mathrm{H}_{13}, \mathrm{CH}_{2} \mathrm{OTBS}, \mathrm{Bn}$ 
In a similar manner, Vicario and coworkers proposed the use of chiral bifunctional secondary amine-squaramide catalysts for the [5+2]-cycloaddition between $\alpha, \beta$-unsaturated aldehydes and oxidopyrylium ylides (Scheme 24). ${ }^{[38]}$ The mechanism of the reaction is based on a dienamine activation of the enal by condensation with amino group, while the bifunctional catalyst also directs the approach of the ylide through the squaramide unit by hydrogen-bonding interactions. Thus, the dienamine intermediate participates as a chiral dipolarophile in the reaction with the in situ formed oxidopyrylium upon elimination of the acetate leaving group, which results in the formation of the 8-oxabicyclo[3.2.1] octane scaffold.

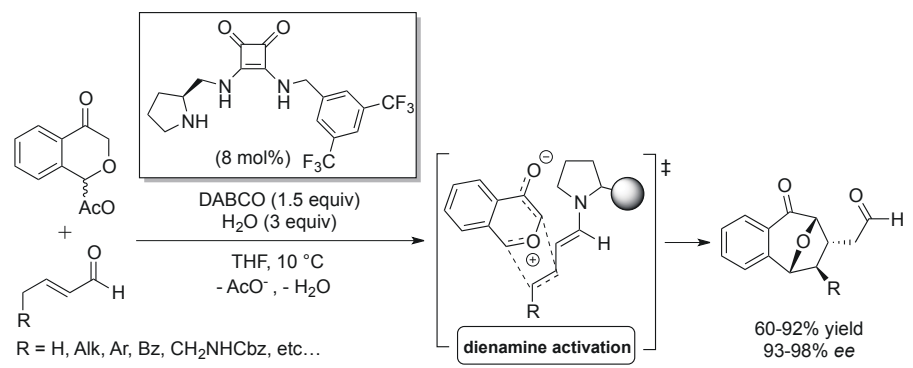

Scheme 24. Enantioselective [5+2]-cycloaddition under dienamine activation.

More recently, an alternative approach for the chiral amino-catalyzed enantioselective [5+2]-dipolar cycloaddition of oxidopyrylium ylides with cinnamaldehydes was reported by Brenner-Moyer and coworkers (Scheme 25). ${ }^{[39]}$ They employed oxidopyrylium dimers as the ylide precursors for the asymmetric cycloaddition reaction with electron-poor dipolarophiles accessible through iminium catalysis using the Jorgensen-Hayashi pyrrolidine catalyst. The oxidopyrylium ylide dimer reactant enabled the use of substoichiometric quantities of both $\mathrm{TfOH}$ as strong acid and $N, N$-diisopropylaniline (DIPEA) as a base, which was critical to attain the best yields, selectivities and reaction times. Hence, excellent enantioselectivities (up to $99 \%$ ee) were achieved.

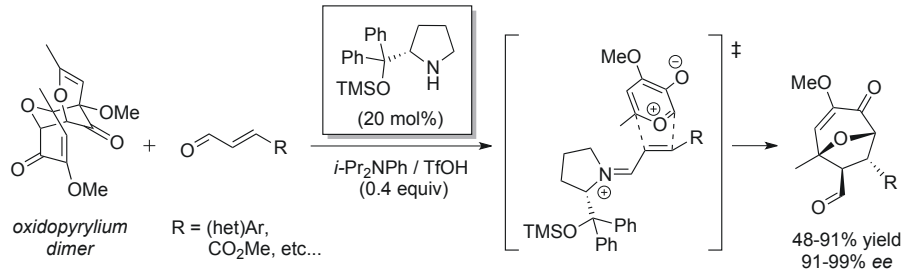

Scheme 25. Amino-catalyzed enantioselective dipolar cycloadditions.

\section{Conclusions}

The application of both metal and organic catalysis for enantioselective reactions of pyrylium species has evolved in recent years into a powerful methodology for the creation of diverse molecular frameworks in a regio- and stereoselective fashion. Most of the approaches employed to date deal with the intrinsic electrophilic nature of the pyrylium salt or dipole character of the related oxidopyrylium derivatives. Thus, enantioselective nucleophilic dearomatization and cycloaddition reactions dominates this research field, leading to single, fused or bridged chiral $O$-heterocycles. However, despite the substantial progress in this field and the applied variety of approaches for the functionalization of pyrylium ions, novel catalytic methodologies applicable in more complex sceneries towards biologically relevant chiral $O$-heterocycles are still of huge interest in the scientific community. Therefore, a substantial advance in this field by the develop- ment of new methods with enhanced stereocontrol and robustness, as well as broader substrate scope, is envisioned in the near future.

\section{Acknowledgements}

S.J. and G.K. acknowledge the financial support by the DAAD PhDprogram.

Received: June 8, 2020

[1] a) A. T. Balaban, A. Dinculescu, G. N. Dorofeenko, G. W. Fischer, A. V. Koblik, V. V. Mezheritskii, W. Schroth, 'Pyrylium Salts: Syntheses, Reactions and Physical Properties', Vol. 2, Academic Press 1982; b) T. S. Balaban, A. T. Balaban, 'Pyrylium Salts', in 'Science of Synthesis', Vol. 15, Georg Thieme Verlag: Stuttgart, 2004, pp 11-200; c) Y. Pang, D. Moser, J. Cornella, Synthesis 2020, 52, 489.

[2] Ø. M. Andersen, K. R. Markham, 'Flavonoids: Chemistry, biochemistry and applications', CRC Press, Taylor \& Francis, 2006.

[3] See for example: a) P. Czerney, G. Graness, E. Birckner, F. Vollmer, W. Rettig, J. Photochem. Photobiol. A: Chem. 1995, 89, 31; b) B. K. Wetzl, S. M. Yarmoluk, D. B. Craig, O. S. Wolfbeis, Angew. Chem. Int. Ed. 2004, 43, 5400 ; c) H. Lv, X.-F. Yang, Y. Zhong, Y. Guo, Z. Li, H. Li, Anal. Chem. 2014, 86, 1800; d) B. Dong, X. Song, X. Kong, C. Wang, Y. Tang, Y. Liu, W. Lin, Adv. Mat. 2016, 28, 8755.

[4] M. A. Miranda, H. García, Chem. Rev. 1994, 94, 1063.

[5] P. N. Moquist, T. Kodama, S. E. Schaus, Angew. Chem. Int. Ed. 2010, 49, 7096.

[6] M. Rueping, C. M. R. Volla, I. Atodiresei, Org. Lett. 2012, 14, 4642.

[7] Y. Luan, Y. Qi, H. Gao, Q. Ma, S. E. Schaus, Eur. J. Org. Chem. 2014, 6868.

[8] S. Handa, L. M. Slaughter, Angew. Chem. Int. Ed. 2012, 51, 2912.

[9] H. D. Srinivas, P. Maity, G. P. A. Yap, M. P. Watson, J. Org. Chem. 2015, 80, 4003.

[10] P. Maity, H. D. Srinivas, M. P. Watson, J. Am. Chem. Soc. 2011, 133, 17142.

[11] L. G. DeRatt, M. Pappoppula, A. Aponick, Angew. Chem. Int. Ed. 2019, 58, 8416.

[12] Y. Guan, J. W. Attard, A. E. Mattson, Chem. Eur. J. 2020, 26, 1742.

[13] D. M. Hodgson, P. A. Stupple, C. Johnstone, Tetrahedron Lett. 1997, 38, 6471.

[14] D. M. Hodgson, P. A. Stupple, C. Johnstoneb, ARKIVOC 2003, 7, 49.

[15] See for example: a) M. P. Doyle, D. C. Forbes, Chem. Rev. 1998, 98, 911; b) H. Suga, H. Ishida, T. Ibata, Tetrahedron Lett. 1998, 39, 3165; c) S. Kitagaki, M. Anada, O. Kataoka, K. Matsuno, C. Umeda, N. Watanabe, S. Hashimoto, J. Am. Chem. Soc. 1999, 121, 1417.

[16] a) H. Suga, K. Inoue, S. Inoue, A. Kakehi, J. Am. Chem. Soc. 2002, 124, 14836; b) H. Suga, K. Inoue, S. Inoue, A. Kakehi, M. Shiro, J. Org. Chem. 2005, 70, 47; c) H. Suga, T. Suzuki, K. Inoue, A. Kakehi, Tetrahedron 2006, 62, 9218; d) H. Suga, S. Higuchi, M. Ohtsuka, D. Ishimoto, T. Arikawa, Tetrahedron 2010, 66, 3070.

[17] D. Hojo, K. Noguchi, K. Tanaka, Angew. Chem. Int. Ed. 2009, 48, 8129.

[18] S.-Y. Yu, H. Zhang, Y. Gao, L. Mo, S. Wang, Z.-J. Yao, J. Am. Chem. Soc. 2013, 135, 11402 .

[19] H. Zhang, L. Zhu, S. Wang, Z.-J. Yao, J. Org. Chem. 2014, 79, 7063.

[20] T. Koshikawa, M. Satoh, K. Masutomi, Y. Shibata, K. Tanaka, Eur. J. Org. Chem. 2019, 1488.

[21] P. I. Dalko, 'Comprehensive Enantioselective Organocatalysis: Catalysts, Reactions, and Applications', Vol. 1-3, Wiley-VCH Verlag, Weinheim, 2013.

[22] a) M. Rueping, D. Parmar, E. Sugiono, 'Asymmetric Brønsted Acid Catalysis', Wiley-VCH Verlag, Weinheim, 2016. See also: b) J. Itoh, K. Yokota, K. Fuchibe, T. Akiyama, Angew. Chem. Int. Ed. 2004, 43, 1566; c) D. Uraguchi, M. Terada, J. Am. Chem. Soc. 2004, 126, 5356.

[23] a) H. Miyabe, 'Hydrogen-Bonding Activation in Chiral Organocatalysts', I. Karame, H. Srour, IntechOpen, 2016. For few selected reviews, see: b) A. G. Doyle, E. N. Jacobsen, Chem. Rev. 2007, 107, 5713; c) M. S. Taylor, E. N. Jacobsen, Angew. Chem. Int. Ed. 2006, 45, 1520.

[24] For a selected review, see: P. Melchiorre, M. Marigo, A. Carlone, G. Bartoli, Angew. Chem. Int. Ed. 2008, 47, 6138.

[25] C.-C. Hsiao, H.-H. Liao, E. Sugiono, I. Atodiresei, M. Rueping, Chem. Eur. J. 2013, 19, 9775.

[26] M. Terada, T. Yamanaka, Y. Toda, Chem. Eur. J. 2013, 19, 13658.

[27] H. Qian, W. Zhao, Z. Wang, J. Sun, J. Am. Chem. Soc. 2015, 137, 560.

[28] Z. Yang, Y. He, F. D. Toste, J. Am. Chem. Soc. 2016, 138, 9775.

[29] P. Proksch, R. Edrada, R. Ebel, F. I. Bohnenstengel, B. W. Nugroho, Curr. Org. Chem. 2001, 5, 923

[30] B. Gerard, S. Sangji, D. J. O’Leary, J. A. Porco, J. Am. Chem. Soc. 2006, 128,7754 .

[31] A. M. Hardman-Baldwin, M. D. Visco, J. M. Wieting, C. Stern, S.-i. Kondo, A. E. Mattson, Org. Lett. 2016, 18, 3766.

[32] T. Fischer, J. Bamberger, M. Gómez-Martínez, D. G. Piekarski, O. García Mancheño, Angew. Chem. Int. Ed. 2019, 58, 3086.

[33] F. Benfatti, M. G. Capdevila, L. Zoli, E. Benedetto, P. G. Cozzi, Chem. Commun. 2009, 45, 5919. 
[34] F. Benfatti, E. Benedetto, P. G. Cozzi, Chem. Asian J. 2010, 5, 2047.

[35] For a review on [5+2]-cycloaddition reactions in organic and natural product synthesis: K. E. O. Ylijoki, J. M. Stryker, Chem. Rev. 2013, 113, 2244

[36] N. Z. Burns, M. R. Witten, E. N. Jacobsen, J. Am. Chem. Soc. 2011, 133, 14578 .

[37] M. R. Witten, E. N. Jacobsen, Angew. Chem. Int. Ed. 2014, 53, 5912.

[38] A. Orue, U. Uria, E. Reyes, L. Carrillo, J. L. Vicario, Angew. Chem. Int. Ed. 2015, 127, 3086.

[39] K. N. Fuhr, D. R. Hirsch, R. P. Murelli, S. E. Brenner-Moyer, Org. Lett. 2017, 19, 6356
License and Terms

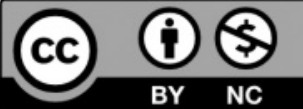

This is an Open Access article under the terms of the Creative Commons Attribution License CC BY_NC 4.0. The material may not be used for commercial purposes.

The license is subject to the CHIMIA terms and conditions: (http:// chimia.ch/component/sppagebuilder/?view=page $\& i d=12$ ).

The definitive version of this article is the electronic one that can be found at https://doi.org/10.2533/chimia.2020.857 